\title{
Human immunodeficiency virus related discrimination in general dentistry
}

Ehab N. Alshouibi, MSD, DScD, Wafa S. AlAlyani, BDS.

\section{ABSTRACT}

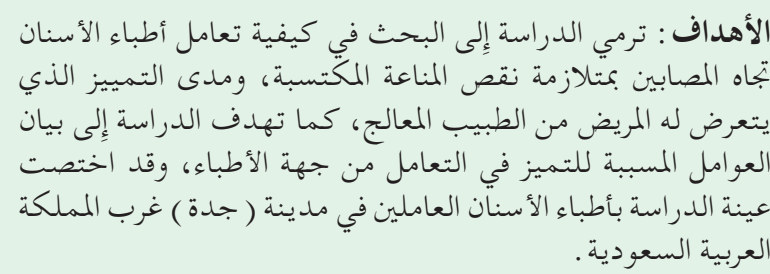

الطريقة : أجريت الدراسة على عينة من أطباء الأسنان في مدينة

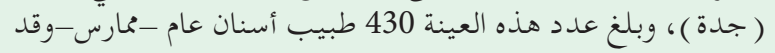

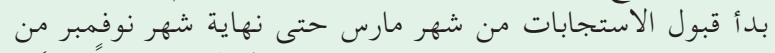

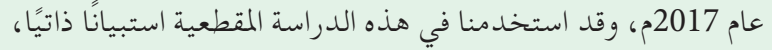

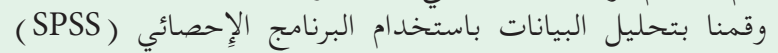

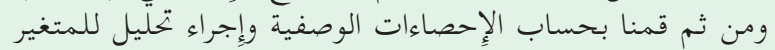

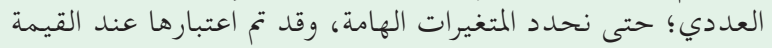

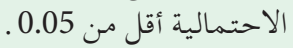

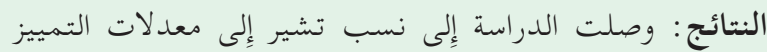

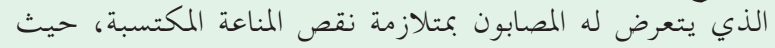

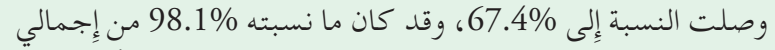

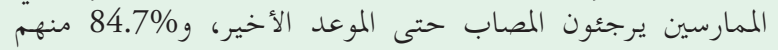

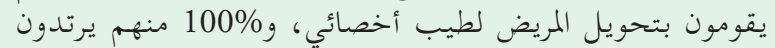

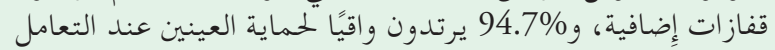

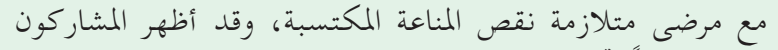

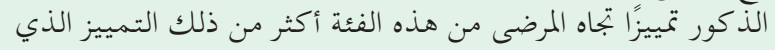

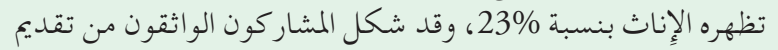

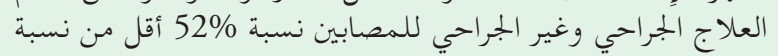

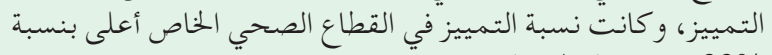
33\% منه في القطاع العام.

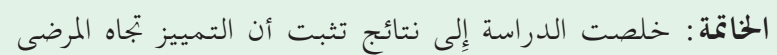

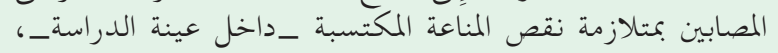

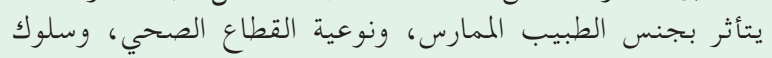
الحماية لدى الممارس الصحيدي لمنارس،

Objectives: To investigate HIV related discrimination among general dentists in Jeddah, Saudi Arabia; and to list factors affecting or causing healthcare providers to discriminate people living with HIV (PLWH).
Methods: The current study takes place in Jeddah, western Saudi Arabia. The duration for accepting all responses was between March and November, 2017. In this cross-sectional study, we used a self-administered, structured questionnaire. The sample size was 430 general dentists practicing in Jeddah, Saudi Arabia. Descriptive statistics, mean, and standard deviation were calculated. Bivariate and multivariate analysis was carried out at $p<0.05$ level of significance. The Statistical Package for the Social Sciences (SPSS) version 22 (IBM Corp., Armonk, NY, USA) was used for data analysis.

Results: In our study population, the total HIV related discrimination was $67.4 \%$. Approximately $98.1 \%$ defer PLWH to the last appointment of the day, while $84.7 \%$ refer them to specialists. Furthermore, $100 \%$ reported wearing double gloves, and $94.7 \%$ where wearing protective eye shields if they encounter HIVpatient in the clinic. Male participants were found to be $23 \%$ more likely to be discriminative compared to female participants, Moreover, participants who are confident to provide both surgical and non-surgical dental treatment for PLWH were found to be $52 \%$ less likely to be discriminative towards PLWH. Also, HIV discrimination is $33 \%$ higher in the private practice compared to the governmental practice.

Conclusion: Human immunodeficiency virus related discrimination in the study population was affected by dentists' gender, type of practice, and self-protective attitudes.

Saudi Med J 2018; Vol. 39 (11): 1148-1153 doi:10.15537/smj.2018.11.23394

From the Dental Public Health Department (Alshouibi), Faculty of Dentistry King Abdulaziz University, Jeddah, Kingdom of Saudi Arabia and School of Public Health (AlAlyani), Faculty of Medicine, Imperial College London, London, United Kingdom.

Received 7th August 2018. Accepted 10th October 2018.

Address correspondence and reprint request to: Dr. Wafa S. AlAlyani, School of Public Health (AlAlyani), Faculty of Medicine, Imperial College London, London, United Kingdom. E-mail: wafasaadz.ws@gmail.com ORCID ID: orcid.org/0000-0002-5161-1472 
$\mathrm{D}$ iscrimination is one of the negative effects caused by HIV stigmatization. ${ }^{1}$ Despite the efforts of recent medical advances that have converted HIV into a manageable chronic disease, HIV discrimination is an important public health and human rights issue. ${ }^{2}$ Although people living with HIV (PLWH) have several healthcare needs that have to be planned effectively, HIV stigma and discrimination was found to negatively impact patients' health and access to healthcare services. ${ }^{3,4}$ Human immunodeficiency virus positive people do not disclose their status out of fear of discrimination, which in turn affects their healthcare access. ${ }^{5}$ In an HIV multi-country study, the prevalence of healthcare discrimination was $10.4 \%$, and the discriminative acts included excessive use of precautions (6.5\%), treatment denial $(3 \%)$, and providing less care $(3.4 \%) .{ }^{6}$ While in a study carried out to investigate HIV discrimination in European healthcare settings, $32 \%$ of the participants reported HIV-related discrimination and half of them experienced discrimination by healthcare providers. Almost 39\% of the reported discrimination was by dentists. Health care providers should be trained to improve their skills in dealing with such a topic without imposing discrimination. ${ }^{7}$ With the advances in HIV antiretroviral therapy, PLWH are living longer. Therefore, their need for oral care is increasing accordingly. ${ }^{8}$ However, care seeking behavior leads PLWH to visit the dental office only when having active symptoms. ${ }^{9}$ In a study carried out to investigate the dental status of HIV-positive patients, the overall dental health was poor. Also, a correlation has been found between the age and duration of HIV involvement with the overall dental health status of the participants. ${ }^{10}$ Barriers that PLWH face in dental settings include complicated administrative work, long waiting times, unwillingness to provide treatment, difficulty to find treating dentists, and having previous psychological problems related to the dental experience. ${ }^{9}$ Moreover, in a study done to investigate HIV-related discrimination in dental settings, a low percentage of stigma and discrimination was observed. However, the majority of the study population did not reveal their HIV diagnosis for fear of rejection. ${ }^{11}$ Saudi Arabia has a conservative culture, where healthcare settings represent an acceptable environment to discuss such an issue. However, most of the HIV-focused epidemiological instruments do not fit

Disclosure. Authors have no conflict of interests, and the work was not supported or funded by any drug company. the conservative Saudi population. ${ }^{12}$ In a study done to assess health rights knowledge among medical students at King Abdulaziz University, only 34.8\% of the study population knew about HIV patient's health rights. ${ }^{13}$ In a study done to investigate the attitudes of dental students in King Saud University towards HIV patients, students' believes were not in line with the code of ethics. About $60 \%$ asked for HIV patients' rooms and beds to be marked, and $28 \%$ considered testing patients for HIV without their permission as acceptable. ${ }^{14}$ This study aims to investigate HIV-related discrimination among general dentists in Jeddah, Saudi Arabia, and to list factors affecting or causing healthcare providers to discriminate against PLWH.

Methods. Online search for prior related research was carried out using the following key words: HIV discrimination, PLWAH, stigma, and discrimination in healthcare. We searched Pubmed and Google Scholar.

The current study took place in Jeddah, western Saudi Arabia, after obtaining ethical approval from King Abdulaziz University Dental Hospital. In this cross-sectional study, a self-administered, structured questionnaire was used. According to the Saudi Commission for Health Specialties census from 2015-2017, the number of registered general dentists in the Kingdom of Saudi Arabia is 5287. We approached all general dentists working in major hospitals and primary health care centers in Jeddah's 5 major districts (North, South, Middle, East, and West). General dentists in the private sector were recruited from private clinics in Jeddah based on the same 5 major districts.

The inclusion criteria of the study population were all practicing general dentists in Jeddah, Saudi Arabia. We excluded any dentist in an administrative position and not actively practicing clinical dentistry. As well as any dental trainee who is not registered as practicing dentist, and dentists with higher training above general dentistry. Participation was voluntary. The participants were approached with an electronic survey version to fill. The duration for accepting all responses was between March and November 2017.

The questionnaire was adopted and modified from previous studies. ${ }^{15-17}$ Distributed in English language. The questionnaire consisted of 4 main sections with a total of 70 questions. The first section was about participant's demographics, followed by a second section devoted to routine infection control and personal protective equipment (PPE). The third section was developed to measure participants' HIV-related 
knowledge. The fourth section assessed the actions and attitude toward PLWH to detect any differential response based on the HIV status of the patients.

Descriptive statistics, mean, and standard deviation were calculated. Bivariate analysis was carried out to identify significant variables $(p<0.05)$. A binary logistic regression model was constructed to estimate the effect of confounding variables on the level of HIV-related discrimination among dental practitioners' as a dependent variable. The dependent variable "HIV-related discrimination" was determined by 20 discrimination-indicating questions. If the participant positively answered 10 or more questions, then the participant was considered discriminating against HIV patients. Five independent confounders were used: participants' gender, type of practice, confidence to provide both surgical and non-surgical dental treatment, HIV-related knowledge, and self-protective attitude against HIV. Both HIV-related knowledge and self-protective attitude against HIV were continuous variables (Table 1).

For data analysis, we used the Statistical Package for the Social Sciences (SPSS) version 22 (IBM Corp., Armonk, NY, USA). The first step in our analysis included running a Chi-square test to explore the significant difference between categorical variable. Secondly, we calculated the odds ratios (ORs) (at 95\% confidence interval) to estimate the relationship and effect of different predictors on HIV-related discrimination; our findings were considered to be significant at $p<0.05$.
Results. Six-hundred general dentists were approached, and 430 agreed to participate, with a response rate of $71.7 \%$. Table 2 represents the demographic data of the study population. Table 3 illustrates the mean and standard deviation of HIV-related knowledge and selfprotective attitude. Table 4 shows Bivariate analysis of

Table 2 - Demographic data of participants.

\begin{tabular}{lc}
\hline Variable & $\%$ \\
\hline Gender & 56.8 \\
Male & 43.2 \\
Female & \\
Type of practice & \\
$\quad$ Private & 46.7 \\
$\quad$ Governmental & 53.3 \\
Action carried out when HIV patient arrived & \\
$\quad$ Defer to the last appointment in the day & 98.1 \\
Refer to a specialist & 84.7 \\
Double Gloves & 100.0 \\
Protective eye wears & 94.7 \\
HIV-related discrimination & \\
Yes & 67.4 \\
No & 32.6 \\
Confidence to provide surgical dental treatment to HIV & \\
patients & \\
Yes & 30.2 \\
No & 69.8 \\
Confidence to provide non-surgical dental treatment to & \\
HIV patients & \\
Yes & \\
No & 48.8 \\
\hline
\end{tabular}

Table 1 - Human immunodeficiency virus related discrimination and self protective attitude questions.

\begin{tabular}{l}
\hline Discrimination questions \\
\hline Feeling comfortable treating HIV patient \\
Feeling comfortable being in physical contact with HIV patient \\
Keeping safety distance from HIV patients \\
Believing HIV patients deserve equal treatment \\
Believing HIV patients require special dental treatment \\
Believing HIV patients should be treated in separate dental setting \\
Modifying the proposed treatment plan for HIV patient \\
Having the right to refuse providing treatment for HIV patient \\
Believing treatment of HIV patient affect practice negatively \\
Having moral obligation to treat HIV patient \\
Having concerns of losing other patients if treating HIV patient \\
Feeling safer when wearing extra PPE \\
Finishing dental treatment faster \\
Scheduling HIV patient for last appointment \\
Sterilizing instrument used on HIV patient separately \\
Having concerns of HIV transmission to other patients \\
Labeling HIV patients' dental records \\
Including HIV patients' status on referral notes \\
Labeling HIV patients' dental impressions \\
Testing for HIV without patient consent
\end{tabular}

PPE - personal protective equipment
Self -protective attitude questions

Keeping mask while talking with HIV patients

Feeling compelled to wash hands after treating HIV patient

Wearing double glove when treating HIV patient

Wearing double mask when treating HIV patient

Wearing protective eye wear when treating HIV patient

Providing simpler dental treatment for HIV patients

Handling dental instrument with extreme care when treating HIV patient

Using special sterilization protocol for the instrument used on HIV patients

Having concerns of contracting HIV when treating HIV patients

Avoiding treating HIV patients

Preferring to refer HIV patients to specialized dentists

Minimizing physical contact with HIV patients

Wearing gloves during all session time even when not providing dental treatment

Testing self for HIV routinely when treating HIV patients 
Table 3 - Mean and standard deviation of HIV-related discrimination and self-protective attitude.

\begin{tabular}{lcc}
\hline Variable & Mean & $\begin{array}{c}\text { Standard } \\
\text { Deviation }\end{array}$ \\
\hline HIV-related knowledge & 7.8 & 5.6 \\
Self-protective attitude & 8.4 & 3.7 \\
\hline
\end{tabular}

Table 4 - Level of discrimination compared between genders and type of practice.

\begin{tabular}{lcccc}
\hline Variables & \multicolumn{2}{c}{ Discrimination } & Total & $P$-value \\
& No & Yes & & \\
\hline Gender & $70(28.7)$ & $174(71.3)$ & $244(100)$ & 0.008 \\
$\quad$ Male & $76(40.9)$ & $110(59.1)$ & $186(100)$ & \\
Female & & & & \\
Type of practice & $73(31.9)$ & $156(68.1)$ & $229(100)$ & 0.001 \\
$\quad \begin{array}{l}\text { Government } \\
\text { Private }\end{array}$ & $37(18.4)$ & $164(81.6)$ & $201(100)$ & \\
$\begin{array}{l}\text { Confidence to provide } \\
\text { both surgical and } \\
\text { non-surgical dental } \\
\text { treatment }\end{array}$ & & & & \\
$\quad \begin{array}{l}\text { No } \\
\text { Yes }\end{array}$ & $38(8.8)$ & $312(72.6)$ & $350(100)$ & $<0.0001$ \\
\hline \multicolumn{5}{l}{ Values are presented as number and percentage (\%) } \\
\hline
\end{tabular}

Table 5 - Logistic regression model of discrimination levels compared to different variables.

\begin{tabular}{|c|c|c|c|c|}
\hline \multirow[t]{2}{*}{ Variable } & \multirow[t]{2}{*}{ Odd ratio } & \multicolumn{2}{|c|}{$\begin{array}{l}95 \% \text { confidence } \\
\text { interval }\end{array}$} & \multirow[t]{2}{*}{$P$-value } \\
\hline & & Lower & Upper & \\
\hline Gender (male) & 1.23 & 1.15 & 1.73 & 0.047 \\
\hline Type of practice (private) & 1.33 & 1.11 & 1.62 & 0.003 \\
\hline $\begin{array}{l}\text { Confidence to provide both } \\
\text { surgical and non-surgical } \\
\text { dental treatment (confident) }\end{array}$ & 0.48 & 0.25 & 0.87 & 0.020 \\
\hline HIV-related knowledge & 0.81 & 0.66 & 0.93 & 0.016 \\
\hline $\begin{array}{l}\text { Self -protective attitude } \\
\text { against HIV }\end{array}$ & 1.37 & 1.20 & 1.79 & 0.002 \\
\hline Constant & 0.006 & & & 0.005 \\
\hline
\end{tabular}

HIV-related discrimination in terms of dentists' gender, type of practice, and confidence to provide both surgical and non-surgical dental treatment.

Male participants were found to be $23 \%$ more likely to be discriminative compared to female participants $(p=0.04)$. Also, HIV discrimination was $33 \%$ higher in the private practice compared to the governmental practice $(p=0.003)$. Moreover, participants who were confident to provide both surgical and non-surgical dental treatment for PLWH were found to be $52 \%$ less likely to be discriminative towards PLWH compared to those who were not confident in providing dental treatment $(p=0.02)$. Nevertheless, a one-unit increase in participants' HIV-related knowledge decreased participants' HIV-related discrimination by almost $19 \%$ $(p<0.01)$. However, a one-unit increase in participants' self-protective attitude against HIV increased the likelihood of participants' HIV-related discrimination by almost 37\% ( $p=0.002)$ (Table 5).

Discussion. The wide social manifestation of HIV-related discrimination includes the healthcare systems. Although some of the discriminative attitudes are institutional, others are personal. ${ }^{18}$ In our study population, the total HIV-related discrimination rate was $67.4 \%$. Human immunodeficiency virus stigma affects patients' health, and PLWH are known to have unmet oral care needs. ${ }^{9,19}$ Oral problems reported by HIV patients include difficulties in eating, sleeping, and maintaining good oral hygiene. ${ }^{20}$ Discriminative attitudes reported by PLWH towards healthcare providers included uncomfortable interactions, irrelevant questions, blame and rude treatments, excessive use of precautions, care refusal, unnecessary referrals, delayed treatment, confidentiality breaches, poor support, labeling PLWH file's to alert other healthcare providers, and fear of occupational infections. ${ }^{21}$ In the current study population, $98.1 \%$ defer PLWH to the last appointment of the day, while $84.7 \%$ refer them to specialists. Furthermore, $100 \%$ reported wearing double gloves, and $94.7 \%$ wear protective eye shields if they encounter a HIV-patient in the clinic. On the other hand, some PLWH reported positive experiences with healthcare providers, such as having equal treatment, being valued, support, being respected and accepted, being assigned to a social worker, and confidentiality assurances. ${ }^{9,21}$ Gender has been found to be a significant variable in the use of PPE, with female dentists reporting higher levels of wearing disposable gowns and protective eye wear. ${ }^{22}$ Also, female participants in our study showed less discriminative attitudes by $59.1 \%$, while male participant showed more discrimination by $71.3 \%$ ( $p=0.008)$. Moreover, male participants were found to be 1.23-times more likely to be discriminative compared to female participants.

In a study carried out to investigate the attitude of dental faculty members towards HIV patients, $86 \%$ were willing to treat and showed ethical responsibility. ${ }^{23}$ Nonetheless, in the current study, general dentists working in the private practice showed a significantly higher rate of $\mathrm{HIV}$-related discrimination $(81.6 \%)$ compared to the governmental hospitals (68.1\%) $(p<0.001)$. Moreover, dentists in private practice 
were 1.33-time more likely to be HIV-discriminative compared to the governmental practice, after controlling for all confounding factors in the study. In a study done to investigate the attitudes of dental students in King Saud University towards HIV patients, about $74 \%$ believed HIV patient status should be disclosed to the partner without permission. Also, 55\% were willing to treat an HIV patient. However, $49 \%$ of the study population reported fears of cross-infection and $10 \%$ of them were not comfortable treating a PLWH's family members. ${ }^{14}$ Among those participants who were not confident in providing both surgical and nonsurgical dental treatment, $72.6 \%$ showed HIV-related discrimination. Among those participants who were confident in providing treatment, $15 \%$ showed HIV-related discrimination $(p<0.0001)$. Moreover, confidence to provide both surgical and non-surgical dental treatment for PLWH reduced discrimination by $52 \%$.

It has been reported that educating and training prospective medical and dental practitioners to improve their knowledge and attitude towards HIV patients represents a useful public health tool. ${ }^{24}$ This is in line with the findings of our study; it has been noted with each one-unit increase in the participants' HIV-related knowledge, there was a decrease (by $19 \%)$ in participants' HIV-related discrimination. Also, with a one-unit increase in participants' selfprotective attitude against HIV; an increased level of participants' HIV-related discrimination (by 1.3-times) was noted. Despite the low levels of HIV prevalence in Saudi Arabia, healthcare providers are a poor source of information for PLWH. ${ }^{25,26}$ Therefore, dental clinics must play a role in educating the population about HIV and the PLWH. ${ }^{27}$ Human immunodeficiency virus discrimination is a hidden obstacle for HIV prevention programs. ${ }^{28}$ Typically, populations with higher levels of education and income have relatively lower levels of HIV-related discrimination. It is crucial to know which interventions for HIV stigma reduction are effective. ${ }^{29}$ The results of a systematic review of interventions to reduce HIV discrimination revealed a lack of consistency of the global scales used to measure stigma and discrimination. Whereas, such a complex issue requires formative interventions, and to further embrace this area of HIV research. ${ }^{30}$ One of the current study limitations was the complete dependence on selfreported data, and therefore, self-reported bias could be a limitation of this study.

In conclusion, HIV-related discrimination in the study population was affected by dentists' gender, type of practice, and self-protective attitudes, whereas confidence to provide a wide scope of dental treatments and to have higher HIV knowledge significantly reduced HIV-related discrimination. Future research could be directed to prevent factors contributing in developing HIV-related discrimination.

\section{References}

1. Deacon H. Towards a sustainable theory of health-related stigma: lessons from the HIV/AIDS literature. Journal of Community \& Applied Social Psychology 2006; 16: 418-425.

2. Grossman CI, Stangl AL. Global action to reduce HIV stigma and discrimination. Journal of the International AIDS Society 2013; 16 (3Suppl 2): 18881.

3. Moradi G, Mohraz M, Gouya MM, Dejman M, Seyedalinaghi S, Khoshravesh S, et al. Health needs of people living with HIV/ AIDS: From the perspective of policy makers, physicians and consultants, and people living with HIV/AIDS. Iran J Public Health 2014; 43: 1424-1435.

4. dos Santos M, Kruger P, Mellors S, Wolvaardt G, van der Ryst E. An exploratory survey measuring stigma and discrimination experienced by people living with HIV/AIDS in South Africa: the People Living with HIV Stigma Index. BMC Public Health BMC Public Health 2014; 14: 80.

5. Rispel L, Cloete A, Metcalf C. 'We keep her status to ourselves': Experiences of stigma and discrimination among HIVdiscordant couples in South Africa, Tanzania and Ukraine. SAHARA J 2015; 12: 10-17.

6. Neuman M, Obermeyer C. Experiences of Stigma, Discrimination, Care and Support Among People Living with HIV: A Four Country Study. AIDS Behav 2013; 17: 1796-808.

7. Nöstlinger C, Rojas Castro D, Platteau T, Dias S, Le Gall J. HIV-related discrimination in European health care settings. AIDS Patient Care STDS 2014; 28: 155-161.

8. Patel N, Furin J, Willenberg D, Apollon Chirouze N, Vernon L. HIV-related stigma in the dental setting: a qualitative study. Special Care in Dentistry 2014; 35: 22-28.

9. Parish C, Siegel K, Pereyra M, Liguori T, Metsch L. Barriers and facilitators to dental care among HIV-Infected adults. Special Care in Dentistry 2015; 35: 294-302.

10. Saravani S, Nosrat Zehi T, Kadeh H, Mir S. Dental Health Status of HIV-Positive Patients and Related Variables in Southeast Iran. Int J High Risk Behav Addict 2016; 5: e29149.

11. Elizondo J, Treviño A, Violant D. Dentistry and HIV/AIDS related stigma. Revista de Saúde Pública 2015; 49: 1-11.

12. Alghabashi M, Guthrie B. Systematic review of human immunodeficiency virus (HIV) knowledge measurement instruments used on the Arabian Peninsula. BMC Res Notes 2015; 8: 646.

13. Al-Amoudi S, Al-Harbi A, Al-Sayegh $\mathrm{N}$ et al. Health rights knowledge among medical school students at King Abdulaziz University, Jeddah, Saudi Arabia. PLoS One 2017; 12: e0176714.

14. Khan S, Liew M, Omar H. Role of ethical beliefs and attitudes of dental students in providing care for HIV/AIDS patients. Saudi Dent J 2017; 29: 7-14.

15. Vorasane S, Jimba M, Kikuchi K et al. An investigation of stigmatizing attitudes towards people living with HIV/AIDS by doctors and nurses in Vientiane, Lao PDR. BMC Health Serv Res 2017; 17: 125. 
16. Feyissa G, Abebe L, Girma E, Woldie M. Stigma and discrimination against people living with HIV by healthcare providers, Southwest Ethiopia. BMC Public Health 2012; 12: 522.

17. Hossain M, Kippax S. HIV-related Discriminatory Attitudes of Healthcare Workers in Bangladesh. Journal of Health, Population and Nutrition. J Health Popul Nutr 2010; 28: 199-207.

18. Chambers L, Rueda S, Baker D et al. Stigma, HIV and health: a qualitative synthesis. BMC Public Health 2015; 15(1).

19. Logie C, Jenkinson J, Earnshaw V, Tharao W, Loutfy M. A structural equation model of HIV-related stigma, racial discrimination, housing insecurity and wellbeing among African and Caribbean black women living with HIV in Ontario, Canada. PLoS One 2016; 11:e0162826.

20. Nasir E, Marthinussen M, Åstrøm A. HIV/AIDS-related attitudes and oral impacts on daily performances: a crosssectional study of Sudanese adult dental patients. BMC Health Serv Res 2013; 13: 335.

21. Stutterheim S, Sicking L, Brands R et al. Patient and Provider Perspectives on HIV and HIV-Related Stigma in Dutch Health Care Settings. AIDS Patient Care STDS 2014; 28: 652-665.

22. Dagher J, Sfeir C, Abdallah A, Majzoub Z. Infection Control Measures in Private Dental Clinics in Lebanon. Int J Dent 2017; 2017: 1-11.

23. Oberoi S, Sharma N, Mohanty V, Marya C, Rekhi A, Oberoi A. Knowledge and Attitude of Faculty Members Working in Dental Institutions towards the Dental Treatment of Patients with HIV/AIDS. Int Sch Res Notices 2014; 2014: 1-10.
24. Kumar V, Patil K, Munoli K. Knowledge and attitude toward human immunodeficiency virus/acquired immuno deficiency syndrome among dental and medical undergraduate students. Journal of Pharmacy and Bioallied Sciences 2015; 7: 666.

25. Mashragi F, Bernstein R, Al-Mazroa M, Al-Tawfiq J, Filemban S, Assiri A et al. HIV transmission at a Saudi Arabia hemodialysis unit. Clinical Infectious Diseases 2014; 59: 897-902.

26. Memish Z, Kasule S, Al-Tawfiq J, Filemban S. Knowledge and attitudes about HIV/AIDS in illegal residents in the Kingdom of Saudi Arabia. J Glob Infect Dis 2015; 7: 103.

27. Toth S, A. York J, DePinto N. HIV stigma: perceptions from HIV-positive and HIV-negative patients in a community dental clinic. J Dent Res Dent Clin Dent Prospects 2016; 10: 263-269.

28. Dahlui M, Azahar N, Bulgiba A, Zaki R, Oche O, Adekunjo $F$ et al. HIV/AIDS Related Stigma and Discrimination against PLWHA in Nigerian Population. PLoS One 2015; 10 : e0143749.

29. Jain A, Nuankaew R, Mongkholwiboolphol N, Banpabuth A, Tuvinun R, Ayuthaya P, et al Community-based interventions that work to reduce HIV stigma and discrimination: results of an evaluation study in Thailand. J Int AIDS Soc 2013; 16 : 18711.

30. Stangl A, Lloyd J, Brady L, Holland C, Baral S. A systematic review of interventions to reduce HIV-related stigma and discrimination from 2002 to 2013: how far have we come? $J$ Int AIDS Soc 2013; 16: 18734. 